\title{
sciendo
}

ISSN: $1231-4005$

e-ISSN: $2354-0133$

DOI: $10.2478 /$ kones-2019-0106

\section{THE EXPERIMENTAL INVESTIGATION OF SURFACE ROUGHNESS AFTER DRY TURNING OF STEEL S235}

\author{
Justyna Molenda \\ Gdynia Maritime University, Faculty of Marine Engineering \\ Morska Street 81-87, 81-225 Gdynia, Poland \\ tel.: +48585586249, fax: +48585586399 \\ e-mail:j.molenda@wm.umg.edu.pl
}

\begin{abstract}
Nowadays lot of scientific work inspired by industry companies was done with the aim to avoid the use of cutting fluids in machining operations. The reasons were ecological and human health problems caused by the cutting fluid. The most logical solution, which can be taken to eliminate all of the problems associated with the use of cooling lubricant, is dry machining. In most cases, however, a machining operation without lubricant finds acceptance only when it is possible to guarantee that the part quality and machining times achieved in wet machining are equalled or surpassed. Surface finish has become an important indicator of quality and precision in manufacturing processes and it is considered as one of the most important parameter in industry. Today the quality of surface finish is a significant requirement for many workpieces. Thus, the choice of optimized cutting parameters is very important for controlling the required surface quality. In the present study, the influence of different machining parameters on surface roughness has been analysed. Experiments were conducted for turning, as it is the most frequently used machining process in machine industry. All these parameters have been studied in terms of depth of cut (ap), feed rate (f) and cutting speed (vc). As workpiece, material steel $S 235$ has been selected. This work presents results of research done during turning realised on conventional lathe CDS 6250 BX-1000 with severe parameters. These demonstrate the necessity of further, more detailed research on turning process results.
\end{abstract}

Keywords: dry turning, turning parameters, turning results, surface roughness, arithmetic average surface roughness value

\section{Introduction}

Increasing the productivity and the quality of the machined parts are the main challenges of metal-based industry. There has been increased interest in monitoring all aspects of the machining process. Surface finish is an important parameter in manufacturing engineering. A characteristic could influence the performance of mechanical parts and the production costs. The ratio between costs and quality of products in each production stage has to be monitored and immediate corrective actions have to be taken in case of deviation from desired trend $[2,6]$.

Turning operation using a single point cutting tool has been one of the oldest and popular methods of metal cutting. It has even replaced grinding in several applications with reduced leadtime without affecting the surface quality. Surface roughness of a turned work-piece is dependent on basic cutting parameters (feed rate, cutting speed, depth of cut) and also on tool geometry: nose radius, rake angle, side cutting edge angle, and cutting edge. In addition, it also depends on the several other exogenous factors such as workpiece and tool material combination and their mechanical properties, quality and type of the machine tool used, auxiliary tooling, and lubricant used, and vibrations between the workpiece, machine tool and cutting tool $[3,5]$.

\section{Dry turning}

The functions of cutting fluid in machining are minimizing the friction between the cutting edge of the tool and workpiece, corrosion control, chip ejection and washing. The application of 
cutting fluid causes significant contamination to the environment and health hazard for the industrial operators and the disposal of used coolants is also difficult according to the federal, state and local laws and regulations. Approximately $15-25 \%$ of total cost of production is spent for coolant.

The vast majority of machining operations exploit the good cooling and lubricating characteristics of cutting fluid. However, as costs for waste disposal increase, companies are now being forced to implement strategies in order to reduce the amount of cutting fluid used in their production lines. The most logical measure, which can be taken to eliminate all of the problems associated with the use of cutting fluid, is dry machining. In most cases, however, a machining operation without lubricant finds acceptance only when it is possible to guarantee that the part quality and machining times achieved in wet machining are equalled or surpassed. The introduction of dry machining techniques may also include the use of minimal quantities of lubricant $[1,7]$.

In a metal turning operation, the maximum amount of heat generated in the cutting zone is carried away by chip and the minimum amount of heat is carried away by workpiece, tool, and cutting fluid if used (Fig. 1). In the absence of cutting fluid, the heat carried away from the cutting zone is decreased, resulting in an increase in tool and workpiece temperature [1].
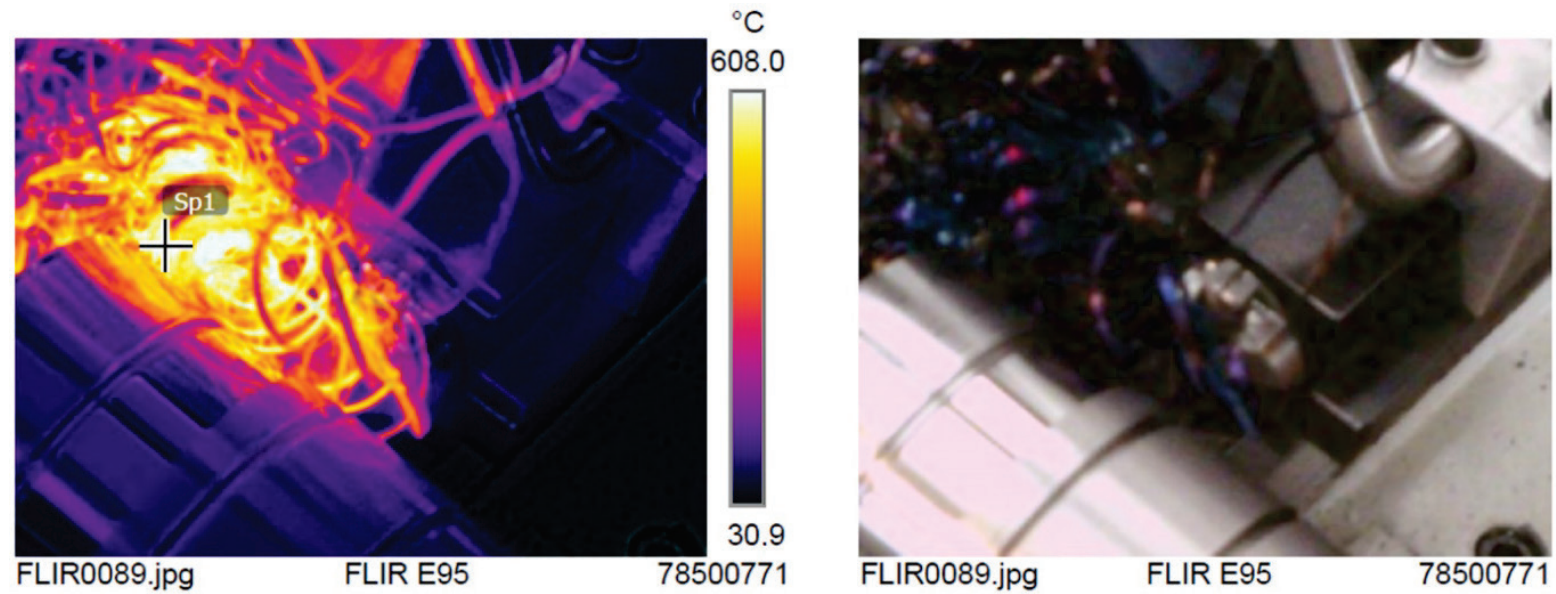

Fig. 1. Temperature distribution in cutting zone during turning [4]

It is well known that the temperature of the cutting tool, the chip, and the workpiece for steel can reach typically level of $750^{\circ} \mathrm{C}$. This should not cause material phase changes, thus it is justified to execute turning process without using coolants. In present study, the influence of different machining parameters on surface roughness has been analysed. Among others, these parameters are Ra (arithmetic mean deviation), Rq (quadratic mean deviation), Rt (total height of roughness profile). All these parameters have been studied in terms of depth of cut (ap), feed rate (f), cutting speed (vc). A S235 steel been selected. To carry out the experiments, Hartley's plan has been used.

\section{Experimental setup}

In this experiment, the conventional lathe CDS $6250 \mathrm{BX}-1000$ were used to conduct the tests without using any coolant. A commercially available turning insert CCMT 09T304 SSP BP30S were used. The machining was performed using workpiece of S235 steel $(250 \mathrm{~mm}$ long and $40 \mathrm{~mm}$ diameter) (Fig. 2).

The surface roughness parameters were measured and recorded with help of Hommel-Etamic W20 surface tester (Fig. 3). W20 is mentioned for both mobile and stationary work. Specification during measurements:

- gauge range: $\pm 300 \mu \mathrm{m}$,

- probe movement (max): $20 \mathrm{~mm}$,

- traverse speed: $0.5 \mathrm{~mm} / \mathrm{s}$. 


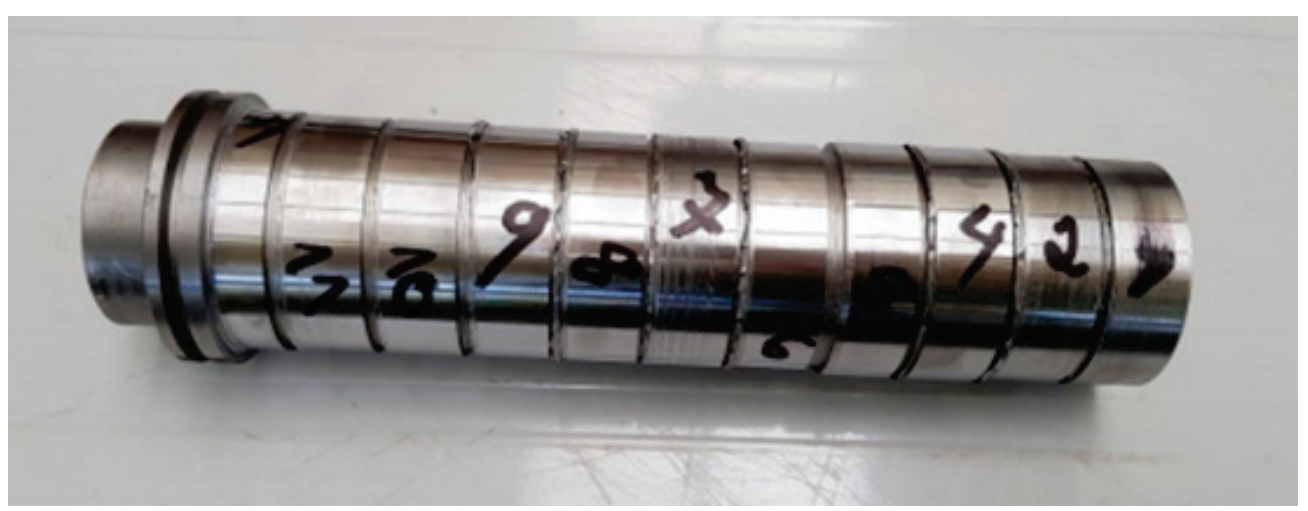

Fig. 2. S235 steel workpiece

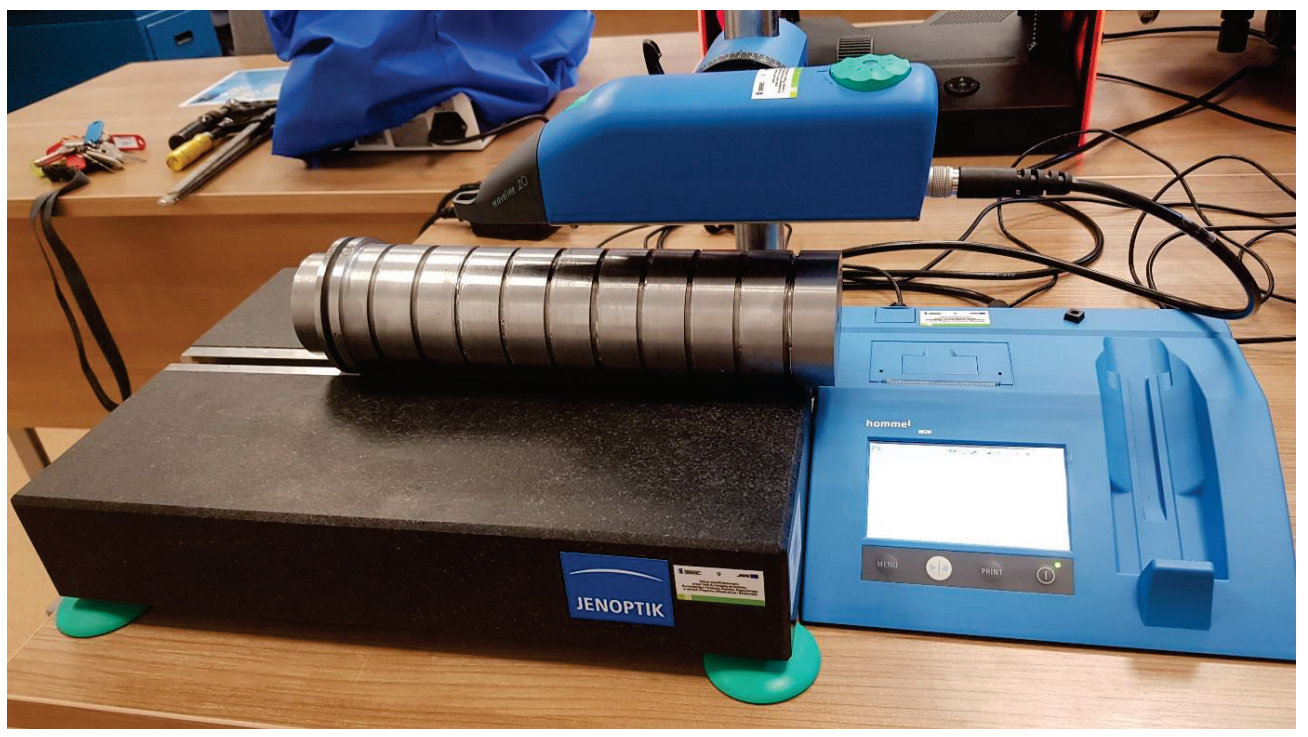

Fig. 3. Hommel-Etamic W20 surface tester

\section{Experiments results}

Tests were conducted for different turning parameters: feed rate (f) differentiated from 0.1 to $0.2 \mathrm{~mm} / \mathrm{rev}$, cutting speed (vc) between 200 and $300 \mathrm{~m} / \mathrm{min}$, and depth of cut ap = 0.5-1.5 mm. As used lathe was conventional, speed values needed to be recalculated to rotation speed (900, 1120, 1350). Design factors and selected levels are shown in Tab. 1.

Tab. 1. Factors and their levels

\begin{tabular}{|l|c|c|c|}
\hline \multirow{2}{*}{\multicolumn{2}{|c|}{ Design Factor }} & \multicolumn{3}{|c|}{ Levels } \\
\cline { 2 - 4 } & Low & Central & High \\
\hline Speed $(\mathrm{m} / \mathrm{min})$ & 200 & 250 & 300 \\
\hline Feed $(\mathrm{mm} / \mathrm{rev})$ & 0.1 & 0.15 & 0.2 \\
\hline Depth of cut $(\mathrm{mm})$ & 0.5 & 1.0 & 1.5 \\
\hline
\end{tabular}

Experiments were executed according to Hartley's experiment plan, shown in Tab. 2. In all cases, the surface roughness was measured at three different locations equally distributed at approximately $120^{\circ}$. In the case of dry turning operation, two different generatrices of the turning cylinders were followed.

Examples of roughness measurement reports before and after turning for the same shaft are presented in Fig. 4, 5 and Tab. 3, 4. 
Tab. 2. Design matrix

\begin{tabular}{|c|c|c|c|}
\hline Shaft number & ap $(\mathrm{mm})$ & $\mathrm{vc}(\mathrm{m} / \mathrm{min})$ & $\mathrm{f}(\mathrm{mm} / \mathrm{rev})$ \\
\hline 1 & 1.5 & 300 & 0.2 \\
\hline 2 & 1.5 & 200 & 0.1 \\
\hline 3 & 0.5 & 300 & 0.1 \\
\hline 4 & 1.5 & 200 & 0.2 \\
\hline 5 & 0.5 & 250 & 0.15 \\
\hline 6 & 1.5 & 250 & 0.15 \\
\hline 7 & 1 & 200 & 0.15 \\
\hline 8 & 1 & 300 & 0.15 \\
\hline 9 & 1 & 250 & 0.1 \\
\hline 10 & 1 & 250 & 0.2 \\
\hline 11 & 1 & 250 & 0.15 \\
\hline
\end{tabular}

Tab. 3. Results of surface parameters measurement for shaft no. 1 before turning

\begin{tabular}{|c|c|c|c|c|}
\hline Number & $\mathrm{Ra}$ & $\mathrm{Rz}$ & $\mathrm{Rt}$ & $\mathrm{Rq}$ \\
\hline 1 & 5.653 & 23.750 & 25.339 & 6.585 \\
\hline 2 & 5.715 & 25.194 & 31.311 & 6.757 \\
\hline 3 & 5.688 & 23.333 & 25.285 & 6.595 \\
\hline Measurement value & $\mathrm{Ra}=5.69 \mu \mathrm{m}$ & $\mathrm{Rz}=23.33 \mu \mathrm{m}$ & $\mathrm{Rt}=25.28 \mu \mathrm{m}$ & $\mathrm{Rq}=6.59 \mu \mathrm{m}$ \\
\hline
\end{tabular}

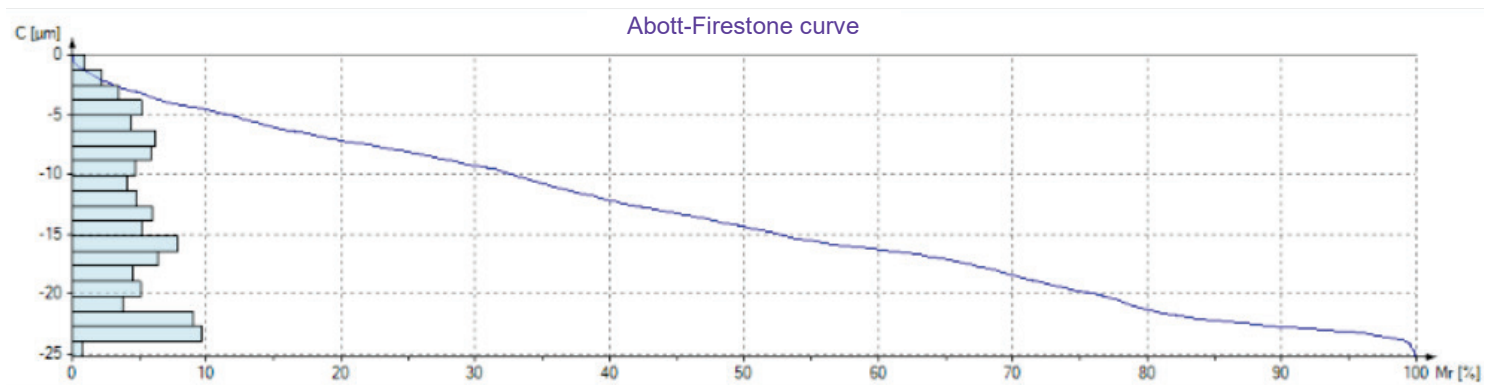

Fig. 4. Results of surface parameters measurement for shaft no. 1 before turning

Tab. 4. Results of surface parameters measurement for shaft no. 1 after turning

\begin{tabular}{|c|c|c|c|c|}
\hline Number & $\mathrm{Ra}$ & $\mathrm{Rz}$ & $\mathrm{Rt}$ & $\mathrm{Rq}$ \\
\hline 1 & 2.894 & 13.000 & 16.562 & 3.368 \\
\hline 2 & 3.052 & 13.919 & 19.277 & 3.594 \\
\hline 3 & 3.118 & 13.598 & 17.641 & 3.592 \\
\hline Measurement value & $\mathrm{Ra}=3.12 \mu \mathrm{m}$ & $\mathrm{Rz}=13.60 \mu \mathrm{m}$ & $\mathrm{Rt}=17.64 \mu \mathrm{m}$ & $\mathrm{Rq}=3.59 \mu \mathrm{m}$ \\
\hline
\end{tabular}

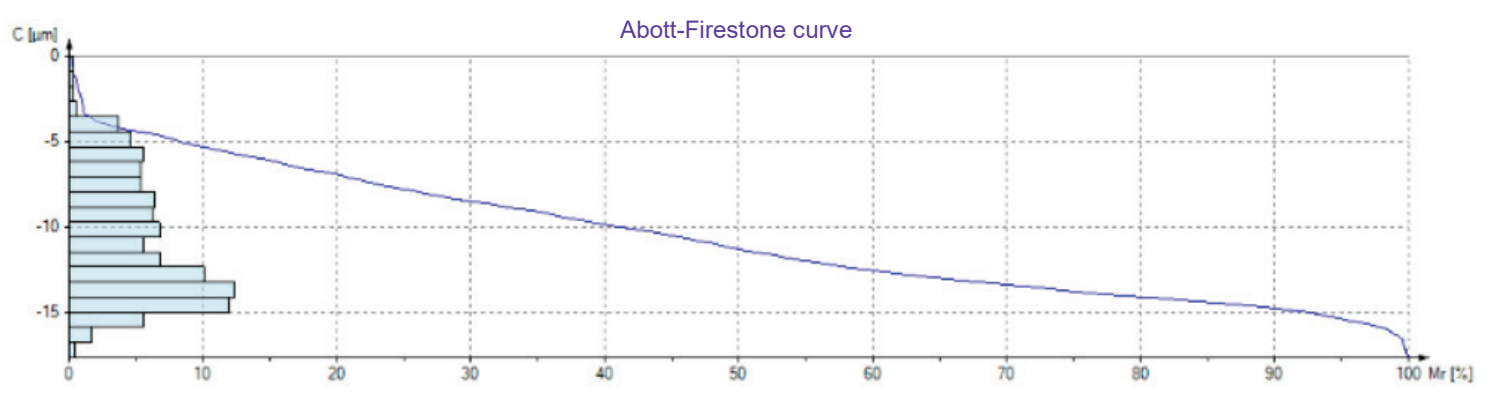

Fig. 5. Results of surface parameters measurement for shaft no. 1 after turning 
Results of surface roughness parameters were presented in Tabs. 5 and 6.

Tab. 5. Results of surface roughness parameters $R a$ and $R z$

\begin{tabular}{|c|c|c|c|c|}
\hline \multirow{2}{*}{ Shaft number } & \multicolumn{2}{|c|}{$\mathrm{Ra}(\mu \mathrm{m})$} & \multicolumn{2}{c|}{$\mathrm{Rz}(\mu \mathrm{m})$} \\
\cline { 2 - 5 } & Before turning & After turning & Before turning & After turning \\
\hline 1 & 5.69 & 3.12 & 23.33 & 13.60 \\
\hline 2 & 6.03 & 1.08 & 24.61 & 5.74 \\
\hline 3 & 5.93 & 2.80 & 26.28 & 11.39 \\
\hline 4 & 5.28 & 2.02 & 27.70 & 9.02 \\
\hline 5 & 1.18 & 2.12 & 8.09 & 8.94 \\
\hline 6 & 0.90 & 2.40 & 5.77 & 13.12 \\
\hline 7 & 4.56 & 2.08 & 17.31 & 8.83 \\
\hline 8 & 2.99 & 1.68 & 15.01 & 6.65 \\
\hline 9 & 6.55 & 1.69 & 27.58 & 8.32 \\
\hline 10 & 6.26 & 1.23 & 26.80 & 8.43 \\
\hline 11 & 6.61 & 0.83 & 31.60 & 4.91 \\
\hline
\end{tabular}

Tab. 6. Results of surface roughness parameters $R q$ and $R t$

\begin{tabular}{|c|c|c|c|c|}
\hline \multirow{2}{*}{ Shaft number } & \multicolumn{2}{|c|}{$\mathrm{Rq}(\mu \mathrm{m})$} & \multicolumn{2}{c|}{$\mathrm{Rt}(\mu \mathrm{m})$} \\
\cline { 2 - 5 } & Before turning & After turning & Before turning & After turning \\
\hline 1 & 6.59 & 3.59 & 25.28 & 17.64 \\
\hline 2 & 6.99 & 1.29 & 25.50 & 7.96 \\
\hline 3 & 7.03 & 3.19 & 28.70 & 12.16 \\
\hline 4 & 6.47 & 2.35 & 36.22 & 11.29 \\
\hline 5 & 1.50 & 2.45 & 10.37 & 9.49 \\
\hline 6 & 1.13 & 2.96 & 7.38 & 22.71 \\
\hline 7 & 5.02 & 2.41 & 24.30 & 9.36 \\
\hline 8 & 3.64 & 1.86 & 21.14 & 7.10 \\
\hline 9 & 7.64 & 2.08 & 35.98 & 8.76 \\
\hline 10 & 7.25 & 1.52 & 28.40 & 11.95 \\
\hline 11 & 7.98 & 1.01 & 50.91 & 5.66 \\
\hline
\end{tabular}

\section{Conclusions}

The goal of this experimental work was to investigate the effects of cutting parameters on workpiece surface roughness. Results show that the most influencing factors are feed rate and depth of cut. The lowest values of all roughness parameters were obtained in medium cutting speed, feed rate, and depth of cut. The worst ones in high cutting speed, feed rate and depth of cut are consistent with dependencies in wet turning. Surprisingly the second worst result has been obtained in high cutting speed, low feed rate and depth of cut, which is different from wet turning.

It shows that further research should be done for detailed investigation of machining process, which realise without cutting liquid.

\section{References}

[1] Klocke, F., Eisenblatter, G., Dry cutting, CIRP Annals, Vol. 46, Iss. 2, 1997. 
[2] Labuda, W., The influence of cutting inserts geometric on surface roughness of steel applied to sea water pump shaft, Journal of KONES Powertrain and Transport, Vol. 22, No. 3, 2015.

[3] Moganapriya, C., Rajasekar, R., Ponappa, K., Venkatesh, R., Karthick, R., Influence of cutting fluid flow rate and cutting parameters on the surface roughness and flank wear of TiAlN coated tool in turning AISI 1015 steel using Taguchi method, Arch. Metall. Mater., Vol. 62, 2017.

[4] Molenda, J., Charchalis, A., Using thermovision for temperature measurements during turning process, Journal of KONES Powertrain and Transport, Vol. 25, No. 4, 2018.

[5] Rao, C. J., Nageswara Rao, D., Srihari, P., Influence of cutting parameters on cutting force and surface finish in turning operation, Procedia Engineering, Vol. 64, 2013.

[6] Suhail, A. H., Ismail, N., Wong, S. V., Abdul Jalil, N. A., Optimization of cutting parameters based on surface roughness and assistance of workpiece surface temperature in turning process, American Journal of Engineering and Applied Sciences, Vol. 3, 2010.

[7] Torres, A., Puertas, I., Luis, C. J., Surface roughness analysis on the dry turning of an Al-Cu alloy, Procedia Engineering, Vol. 132, 2015.

Manuscript received 16 August 2019; approved for printing 05 December 2019 